\title{
ACTUALIDAD DE LAS BUCÓLICAS Y LAS GEÓRGICAS DE VIRGILIO
}

\begin{tabular}{c} 
Carlos Gatti $^{*}$ \\
Universidad del Pacifico \\
\hline
\end{tabular}

Fecha de recepción: septiembre de 2012 Fecha de aceptación: octubre de 2012

ReSUMEN: En este trabajo el autor analiza la actualidad de la obra de Virgilio para el lector de hoy. Se centra en las Bucólicas y las Geórgicas, poemas que son resultado de un verdadero proceso educativo del poeta latino. En estas obras, Virgilio representa la complejidad de la vida en el mundo ideal de los pastores, y muestra al hombre que no se limita a aprovechar lo que la naturaleza ofrece o lo que la casualidad trae consigo, sino que actúa y produce. Virgilio recuerda, en ese sentido, una labor del ser humano que exige armonía y paz, con la naturaleza y con el prójimo.

Palabras clave: Virgilio, poesía, Bucólicas y Geórgicas, literatura latina.

Carlos Gatti Murriel realizó estudios en la Facultad de Letras de la Pontificia Universidad Católica del Perú, sección Doctoral de Literatura. Siguió cursos en el Instituto Lingüístico Latinoamericano de la Universidad de la República (Montevideo, Uruguay). Ejerce la docencia en la Universidad del Pacífico y la Pontificia Universidad Católica del Perú, donde dicta cursos de Literatura. Entre 1987 y 2009 desempeñó el cargo de Secretario General de la Universidad del Pacífico. Es miembro de la Dante Society of America, del Instituto Riva-Agüero de la Pontificia Universidad Católica del Perú, de la Sociedad Peruana de Estudios Clásicos y de la Sociedad Filarmónica de Lima, cuyo Consejo Directivo integra actualmente como Coordinador de Actividades Institucionales.

Ha publicado diversos artículos sobre temas literarios y musicales. Es coautor de textos universitarios relativos al lenguaje (Elementos de gramática española; Técnicas de lectura y redacción; El lenguaje. Dos aproximaciones), coautor del libro Derecho y Literatura, y autor de dos libros: uno sobre temas de educación (El eslabón del día) y otro sobre temas musicales (Franz Liszt, peregrino de la vida y el arte). 
AвSTRACT: In this paper, the author analyzes the topicality of Virgil's work for today's reader. He focuses on the Eclogues and the Georgics poems which are the result of a real educational process of the Latin poet. In these masterpieces, Virgil represents the complexities of life in the ideal world of shepherds, and shows that man does not only take advantage of nature and chances, but he also acts and produces. In that same sense, Virgilio reminds us about the human being's labor that demands to be in harmony and peace with nature and with our fellows.

KeYwords: Virgil, poetry, Bucolics and Georgics, Latin literature

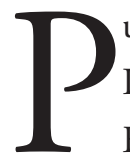

uede parecer curioso que en una época y en un lugar tan distante, en Lima, en el siglo xxI, Virgilio siga teniendo presencia y actualidad. Eso se debe al hecho de que él es uno de esos pocos grandes autores que logran sobreponerse a las ataduras de la inmediatez, de las circunstancias, y saben crear obras y mensajes significativos para las diversas épocas. Tales son los grandes espíritus clásicos. Allí están Homero, Virgilio, Dante, Cervantes, Shakespeare, Goethe. Sin abandonar a sus circunstancias, más, a partir de ellas, saben leer e interpretar los grandes temas de la humanidad, es decir, son capaces de encarar lo que siempre tiene vigencia y de interpelar a los hombres y mujeres de todos los tiempos. Así, ellos se convierten en maestros y guías de la posteridad.

Un gran ejemplo de eso fue el caso de Homero. Él influyó en su sociedad: plasmó los modelos de los hombres excelentes y virtuosos que sirvieron para educar a los griegos del siglo viII en los ideales de la areté (de la virtud, de la excelencia), y permitieron construir las élites que constituyeron la aristocracia (el sistema en el cual el mando estaba en manos de los virtuosos, excelentes). Más allá de esa importante repercusión sobre la sociedad del siglo viıI a.C., Homero, siglos después, influyó en Virgilio. A propósito de 
ello, Jorge Luis Borges, en el libro Biblioteca personal, cita a Voltaire, quien escribió: «si Virgilio es obra de Homero, éste fue de todas sus obras la que le salió mejor» (Borges 1999:154). Esa opinión adquiere especial significación si se considera que fue sostenida por el pensador francés en una época en la que se desdeñaba a Virgilio y se quería verlo como simple imitador de Homero.

Tal fue la importancia de Virgilio a lo largo de tantos siglos después de su muerte, que Dante Alighieri lo tomó como su guía, su maestro, su padre, y hasta su autor, según testimonia en la Comedia. Podemos decir que fue su «autor» tanto porque Virgilio reunía la condición de autoridad para enseñar, como porque moldeó a Dante como literato y como hombre que buscaba el sentido profundo de la vida y la muerte. Así son los clásicos. Ellos perduran y actúan como «autores» pues educan como maestros a discípulos distantes, quienes a su vez, podrán convertirse en nuevos maestros.

\section{EL CANTOR DE ENEAS}

Publio Virgilio Marón (o Publius Vergilius Maro) fue el nombre completo de nuestro autor. La identificación mediante el nombre era muy precisa entre los ciudadanos romanos. Publio designaba al individuo; Virgilio, a la gens (o grupo de familias) y Marón, a la familia.

Vivió en el siglo I antes de Cristo, en la trágica y sangrienta época de la decadencia de la República Romana y de la gestación del nuevo orden creado por Octavio, quien dio origen al Imperio mediante el cual prolongó por varios siglos el poder de Roma.

Vino a la vida Virgilio el 15 de octubre del año 70 a. C., en los idus de octubre, después llamados idus de Virgilio. Era la época del consulado de Pompeyo y Craso. El lugar de su nacimiento fue Andes, localidad cercana 
a Mantua, ubicada en el norte de Italia, en la actual Lombardía. Esa región, que había sido poblada por etruscos, luego por celtas y finalmente por colonos latinos, alcanzó el derecho de ciudadanía romana solo el año 51, cuando Virgilio estaba por sus 19 años. Allí, el padre de Virgilio poseía una propiedad rural, en la cual el poeta creció. En el rico campo mantuano, desarrolló su amor a la «Madre Tierra», al paisaje de la región, feraz espacio formado por bosques, campiñas, ríos y lagunas, escenario propicio para la agricultura y la ganadería. Ese amor se mantuvo a lo largo de toda la vida del poeta. Teodoro Haecker, autor del libro Virgilio Padre de Occidente, evoca a Varrón quien consideraba que el campo había sido otorgado a los hombres por los mismos dioses, mientras que las ciudades eran obra de los hombres. Cabe preguntarse qué era lo que Virgilio, hijo del campo regalado por los dioses, podía observar en la ciudad creada por los hombres. Él, que había vivido en el perfecto orden de la naturaleza, ¿qué veía fuera de ese orden en el escenario urbano, allí donde se decidía la construcción de la historia? Veía que desde hacía décadas se sucedían guerras sangrientas, crímenes políticos, matanzas colectivas. Dejando de lado las numerosas campañas bélicas y los conflictos interminables entre caudillos, basta recordar, a modo de ejemplo, la ejecución de tres mil partidarios de los Gracos, la crucifixión de seis mil seguidores de Espartaco, la matanza de siete mil prisioneros samnitas ante el Senado reunido. Sumemos a ello los asesinatos de César y de Cicerón.

"iA qué extremos ha llevado la discordia a los miserables ciudadanos!», dice en un pasaje la primera Bucólica de Virgilio (versos 7172) refiriéndose a aquella época.

A los 12 años, el poeta latino comenzó estudios en Cremona y en Milán. Luego, a los 16 años, se trasladó a Roma. Era el año 54. En esta ciudad los partidarios de César y de Pompeyo, luego de la muerte de Craso, suscitaban grandes disturbios. Virgilio no se adscribió a ninguna de las 
facciones en pugna. Por esa época murió el poeta Catulo y Cicerón publicó De rerum natura, gran obra de Lucrecio. Tanto Catulo como Lucrecio influyeron entonces notablemente en Virgilio. Catulo había dado especial impulso a la lírica latina, y, según Haecker, en él «aprendió el joven Virgilio a componer versos». «Lucrecio..., le enseñó que una poesía grande tiene que traspasar el límite del elemento primitivo de lo poético -es decir, lo lírico y la vida sensible y anímica de la naturaleza, correspondiente a lo lírico y captada inmediatamente- en alas de una filosofía y, a poco, también de una teología» (Haecker 1945:51).

Según el mismo Teodoro Haecker, "Virgilio pretendió en Roma lo que en Roma pretendía todo provinciano inteligente y ambicioso: emprender la carrera política; es decir, pretendió hacerse abogado; pero era in sermone tardissimus, lento y torpe en el hablar, con un alma demasiado amplia» (1945:56-57). Eso significó que tuviese que cambiar de propósito, y abandonó Roma a los veinte años.

Más adelante, y como no podía ir a Grecia a estudiar por falta de recursos, se dirigió a Nápoles, ciudad que se jactaba de poseer cultura y educación griegas. Allí se instaló por cinco años y estudió en la escuela filosófica de Sirón, un epicúreo. Se encontraba en esa ciudad cuando se enteró tanto de los terribles hechos de la guerra civil entre Pompeyo y César, como, luego, del triunfo de César. Por aquella época, Virgilio se empapó de poesía griega y de la cultura de los poetas neotéricos. El Neoterismo fue un movimiento poético desarrollado durante los últimos años de la República Romana. El nombre de tal corriente literaria se debe a la ironía de Cicerón, quien los llamó así aludiendo a su modernidad. Más adelante y conforme fue madurando su personalidad, Virgilio se alejó del experimentalismo neotérico que tomaba como modelos a Calímaco y la poesía alejandrina. 
En este punto cabe recordar lo que plantea René Johannet en un estudio titulado «Virgilio y nosotros» a propósito del mérito de la creación original dentro del marco de los convencionalismos imitativos. «Con semejantes normas directivas (dice) no podían sobresalir sino las originalidades macizas, absolutas, inconscientes y por lo mismo desbordantes. Para superar tales trabas hacía falta un alma realmente superior, un arte sin par. Tal fue evidentemente el caso de Virgilio» (Espinosa 1932:134).

Por ello, el gran humanista ecuatoriano, el padre Aurelio Espinosa Polit, jesuita autor de una afamada traducción de la obra de Virgilio y notable estudioso de este poeta, sostiene que Virgilio "produjo en sus contemporáneos una intensa impresión de novedad. Nuevas las Bucólicas, que sacaban a la poesía erudita del estrecho callejón del alejandrinismo y hacían resonar una música desconocida, exquisitamente juguetona y tierna» (Espinosa 1932:135). Espinosa se refiere luego a las Geórgicas, en las cuales también reconoce novedad en su visión «al mismo tiempo tan realista y tan divinamente ideal del campo [...], con su clamor de alarma y su himno de esperanza» (Espinosa 1932:135)

Probablemente el año 39 Virgilio conoció y trabó amistad con Mecenas, allegado al poder político cuyo nombre queda perennizado en nuestro idioma, y en otros, para aludir a quien es protector de las letras y de las artes. A partir de entonces, la obra poética de Virgilio está asociada a Mecenas y se va comprometiendo con los ideales de la romanidad y los propósitos renovadores, pacifistas y civilizadores de Octavio, luego llamado Augusto. Tal compromiso daría como máximo fruto a la Eneida, la gran epopeya virgiliana que ocupó al poeta hasta los últimos días de su vida.

Después de un viaje a Grecia, adonde había querido ir para conocer lugares mencionados en la Eneida, el año 19 a.C., cuando él contaba con 51 años, desembarcó gravemente enfermo en Bríndisi, puerto ubicado en el 
sur de Italia, en una región a la que antiguamente se reconocía como parte de Calabria. Allí murió. Su cadáver fue trasladado a Nápoles (la ciudad Partenopea), en la cual había pasado varios de los años más productivos de su vida. La inscripción funeraria escrita para Virgilio recoge las siguientes palabras que resumen su biografía.

\section{Mantua me dio la vida, Calabria me la robó,} me guarda ahora Parténope. Canté los pastos, los campos, los capitanes.

En tal inscripción no solo se alude a los lugares asociados a hechos fundamentales de la vida, como en el nacimiento (Mantua), la muerte (Bríndisi, Calabria), y el descanso en paz (Parténope, Nápoles). También se alude a la evolución de su obra. En efecto, Virgilio, poeta, cantó a tres mundos: el de los pastores, el de los agricultores (o labriegos) y el de los caudillos (héroes conductores de los pueblos mediante su acción directa y mediante su ejemplo). La obra grande de Virgilio se desarrolló en tres momentos y se centró en tres tipos de personajes que encarnan modelos diversos de sociedad: el del hombre que ambula con sus rebaños (Bucólicas), el del agricultor que cocrea con la naturaleza (Geórgicas) y el del héroe (Eneas) que guía a un pueblo en su viaje hacia una tierra prometida en un éxodo largo y difícil y que no acaba en el simple hecho de llegar a un lugar, ya que es indispensable enfrentar a muchos retos para reconstruir la grandeza de la antigua Troya en una nueva ciudad, la futura Roma (ese es el caso de la Eneida). Tal fue el éxito que alcanzó la obra de Virgilio a lo largo del tiempo, que estas tres obras se convirtieron en modelos para los siglos posteriores. En efecto, ellas sirvieron de referencia para determinar las características y las convenciones retóricas correspondientes a cada uno de los tres estilos. Las Bucólicas se tomaron como modelo del llamado «estilo 
humilde» o «bajo»; las Geórgicas encarnaron al «estilo medio», y la Eneida fue la base del «estilo sublime» o «elevado».

\section{LAS BUCÓLICAS Y LAS GEÓRGICAS}

El año 44 a.C. se produce el famoso asesinato de Julio César en el Senado. Este es un grave acontecimiento enmarcado en la atmósfera de guerras y violencia que caracteriza por décadas a la decadente República Romana. El 43, año de los combates de Módena entre tropas del Senado y tropas de Marco Antonio, Octavio asume la función de Cónsul, y se constituye el Segundo Triunvirato, formado por él, Antonio y Lépido. El 42 tiene lugar la batalla de Filipos, en la que se enfrentan los cesarianos (Antonio y Octavio) y los defensores de la República (Bruto y Casio); y el 41 se producen las guerras de Perugia, entre Octavio y los partidarios de Antonio. La estabilidad política, pues, no existe: el conflicto permanente parece ser el sino de Roma y del hombre, ya que los aliados de antes se separan y se enfrentan cuando desaparece el enemigo común. El año 36 el tercer triunviro, Lépido, es depuesto, lo que indica que el Segundo Triunvirato ha fracasado, como años atrás había sucedido con el primero.

Los años a los que nos hemos referido corresponden al período en el cual Virgilio gesta las Bucólicas. Él, apartado del fragor de las batallas, está refugiado en su heredad familiar de Mantua, su tierra natal, donde disfruta del paisaje idílico y del sustento que este le brinda. Allí, el año 43 inicia la escritura de la obra. Entre el 43 y el 40 redacta cuatro de los diez poemas pastorales que constituyen las Bucólicas. Con el transcurso de los años, la obra queda completa y se publica el 37. Durante ese lapso, Virgilio es afectado por la confiscación de sus tierras, las que pasan a manos de militares veteranos que exigían tierras después de la batalla de Filipos. El 40 el poeta 
pierde su finca. Más delante, como consecuencia de un viaje a Roma, y por obra de Octavio, Virgilio recupera sus tierras. Durante su estancia en Roma, en aquellos días, el poeta es testigo del creciente conflicto entre Octavio y Antonio, el cual terminará unos años después con la derrota de este último.

Las Bucólicas presentan al mundo idílico de los pastores, el mundo de Teócrito que Virgilio había conocido por sus estudios juveniles, de la época en la que se había empapado de literatura alejandrina, de filosofía epicúrea y del movimiento neotérico. Sin embargo, las Bucólicas son mucho más que una imitación o una simple ilustración de un sistema filosófico. Todo lo aprendido ha sido digerido y asimilado para alimentar a una nueva vida, a una realidad literaria que se construye en el contraste entre los sueños y el drama renovado cada amanecer tal vez con tintes más oscuros. Como señala Julio Picasso, «la filosofía epicúrea empieza a resquebrajarse». ${ }^{1}$ También destaca cómo a la frase de inspiración epicureísta «su propio placer arrastra a todos» (tomada de la II bucólica) se contrapone la expresión «la Fortuna todo lo trastorna» (incluida en la Ix bucólica). Precisamente en la ix bucólica, detrás del diálogo sereno, está el drama que a Virgilio le ha originado la confiscación de sus tierras y el abuso de los fuertes.

Con las Bucólicas, Virgilio creó una obra en la cual se muestra una gran evolución. De la perspectiva del hombre solitario y refugiado en el paisaje idílico se pasa a otra dimensión que implica niveles más elevados de humanidad. La obra no se limita a presentar las confesiones o los diálogos relativos a las penas o los júbilos generados por el amor de un pastor que se fija en otra persona y se limita a la pasión que ella le suscita. En las Bucólicas también resuena la voz que se eleva con peculiares acentos en busca de un

Prólogo a su edición de Virgilio. Bucólicas y Geórgicas (Lima: Fondo Editorial UCSS, 2004, p. 7). 
amor que envuelva a todas las cosas, que apunte a la armonía del mundo. Eso induce a soñar con la Edad de Oro, con el resurgimiento del amor, la paz y el progreso. Así, la bucólica IV anuncia el advenimiento de un nuevo orden y presenta el nacimiento de un niño que asistirá al cambio de la faz del mundo. Ya no se trata del amor limitado a la pasión carnal, sino del amor en su sentido más amplio, el amor extendido a la totalidad. Más allá de limitarse a ofrecer presentimientos de tiempos nuevos, en la bucólica IV se vislumbra un arcano divino. En tal obra la poesía, la palabra, recibió un aliento teológico. Tal vez por ello, el Cristianismo vio en la cuarta bucólica un anuncio del nacimiento de Cristo, e hizo de Virgilio un profeta.

Los pastores de Virgilio son idealizaciones. Son como poetas huidos de la ciudad para refugiarse en la tranquilidad del campo. El modelo inicial para Virgilio fue el siracusano Teócrito. Sin embargo, en las Bucólicas, el espacio literario del paisaje siciliano de Teócrito adquiere rasgos propios del paisaje del norte de Italia, concretamente de la región de Mantua, la patria chica de Virgilio. Asimismo, Virgilio, que parte de la idealidad de Teócrito, encuentra en el dolor un elemento definitorio de su mundo poético, en el cual la violencia de la historia contrasta con la Arcadia de los hombres que viven en paz dedicados al trabajo, en una religiosa aceptación de su suerte.

Rubén Bonifaz Nuño escribe las siguientes líneas que me parecen inspiradoras:

La naturaleza representa el sumo bien en tanto que se identifica con el Señorío del ser humano sobre sí mismo [...], el hombre hace suyo el mundo natural, lo identifica consigo mismo [...] y con la naturaleza se hace íntegro y libre. La edad de oro viene a ser [...] el símbolo máximo de la libertad. Durante ella es creado un mundo en que el hombre, dueńo de una naturaleza dócil y 
servicial, adquiere mediante ella el dominio de sí mismo, y con éste la sabiduría, la templanza y la paz. (1967:21)

Inspirados en tales ideas, podríamos decir que el deseo de la Edad de Oro es la aspiración de un futuro en el que el hombre reconciliado adquiere la libertad por ser dueño de sí mismo. En contraste, en la vida corriente de la Edad de Hierro, la libertad es recortada por factores externos, como la guerra y la injusticia, o por factores internos, como el amor pasional o la ambición. Frente a ello, la amistad es una forma de ejercicio de la libertad que ayuda a alcanzar la felicidad de los hombres si se esfuerzan por lograr una meta superior.

Pasemos ahora a observar la estructura de las Bucólicas. Ella es el resultado de una inteligente arquitectura elaborada por el gran poeta latino, cuya voluntad de forma es innegable. La obra incluye diez bucólicas escritas en hexámetros.

El conjunto de las nueve bucólicas concebidas inicialmente responde a un ordenamiento muy sugerente basado en la correspondencia entre la serie que va de la primera a la cuarta y la serie que regresivamente va de la novena a la sexta. Eso quiere decir que la voluntad ordenadora de Virgilio busca una correspondencia entre la I y la IX, la II y la VIII, la III y la VII, la IV y la vi. La quinta actúa como eje o centro de la admirable arquitectura.

Las Bucólicas I y IX son diálogos vinculados con la experiencia histórica de Virgilio relativa a la confiscación de terrenos que siguió a la batalla de Filipos. Ambas, pues, se refieren al padecimiento originado por la injusticia.

La II y la viII son monólogos centrados en el sufrimiento ocasionado por el amor pasional. 
La iII y la VII, que son cantos amebeos, «proponen el sentimiento amistoso como una solución libertadora» (Bonifaz 1967:22). Julio Picasso reconoce en ellas la presencia de la música liberadora.

La IV y la VI, que adquieren carácter de monólogos míticos, «contraponen la esperada perfección de la naturaleza y el desorden creado por el ciego e irracional impulso de las pasiones humanas» (Bonifaz 1967:22). Según Julio Picasso, la Iv presenta una revelación mítica sobre el futuro, y la vi una sobre el pasado.

La v, centro de todo el conjunto arquitectónico, ofrece el desarrollo cumbre sobre el sentimiento amistoso como solución liberadora. Ella incluye el elogio de Dafnis, semidiós inventor de la pastoral y figura emblemática de la bucólica siciliana. Mientras Teócrito (Idilio 1) presenta a Dafnis como ser humano en agonía, Virgilio lo ve, después de muerto, como héroe y semidiós, homologado al culto de Orfeo. Dafnis es el mítico pastor siciliano aparecido en un momento en que la peste azotó a Sicilia. En esta Bucólica Virgilio ha llegado a la Arcadia, el mundo ideal, pero partiendo de su Mantua natal y pasando por Sicilia, la tierra de Teócrito y Dafnis.

La $\mathrm{x}$ resume el carácter de las Bucólicas. Añadida a las nueve inicialmente previstas, se inspira en la circunstancia lamentable que vivió Cornelio Galo, poeta elegíaco y amigo de Virgilio. Esta bucólica reúne variados aspectos: el pesar por el abandono de la patria, el sobrecogimiento de la naturaleza y su compasión por los sufrimientos del hombre, la solidaridad humana ante el dolor de la persona, y las ataduras que crean la pasión y la injusticia. Tal como destaca Julio Picasso, este poema es, a la vez, exaltación y crítica del género en el que ha sido concebida, es decir, del pastoral. n él, el poeta ya maduro trasciende las limitaciones del género y transmite los sentimientos y las ideas de personas que ya no tienen necesidad de esconderse tras disfraces de pastores y no temen nombrarse. 
Por ello, podríamos considerar que si la v bucólica creó el clímax, a esta, la $\mathrm{x}$, corresponde el anticlímax.

No debo extenderme más hablando de las Bucólicas; sin embargo, no puedo dejar de mencionar que cada una de las diez partes que integran esta obra ha sido elaborada con un extraordinario sentido de la arquitectura y la simetría.

Ahora paso a referirme brevemente a la segunda obra de Virgilio, a las Geórgicas. Antes de hacerlo, deseo destacar el valor del prólogo escrito por Julio Picasso para presentar su traducción. Hay en él un concentrado de información y una interesante hipótesis sobre el proceso de formación de esta obra virgiliana.

Virgilio conoció a Mecenas cuando fue a Roma movido por el deseo de recuperar las tierras que le habían sido confiscadas. Parece que la segunda obra del poeta, las Geórgicas, fue un encargo de Mecenas, personaje allegado a Octavio, con cuyos propósitos políticos estaba muy comprometido. Por aquellos años se ahondaba la enemistad entre Octavio y Antonio, la cual desembocó en enfrentamientos que culminaron con la batalla de Actium, el año 31. El año siguiente, el 30, se produjo la muerte de Antonio y de Cleopatra, quienes habían puesto en riesgo el poder romano. El 29 apareció la segunda obra de Virgilio, las Geórgicas, dos años antes de que Octavio pasase a ser Augustus, el creador del nuevo orden imperial, universal y pacífico que aspiraba a cumplir una función civilizadora del mundo. Para ello se necesitaba devolver a los romanos a los ideales de la romanidad, el amor a la patria, la restauración del principio de autoridad, el renacimiento de los valores asociados a la religión y al trabajo.

Solo en ese marco era posible crear la paz y la prosperidad. El espíritu renovador debería extenderse a todos los terrenos, entre ellos el administrativo, el judicial y el económico. Era, pues, importante que los 
romanos volvieran al campo y lo hicieran productivo mediante el trabajo. Las Geórgicas tenían una cabida especial en ese programa.

Como menciona Julio Picasso en el prólogo de su traducción de las Geórgicas, por el interés de Octavio y de las diversas clases sociales romanas por volver a la agricultura, se desenterraron muchos tratados agronómicos escritos por griegos, fenicios y romanos, y se escribieron otros nuevos. Virgilio concibió un poema didáctico inspirado en el modelo de Los trabajos y los días de Hesíodo, que conoció en una versión amplificada por autor anónimo, hoy perdida. Influyeron en la concepción de las Geórgicas autores como Arato, con Fenómenos; Lucrecio, con el De rerum natura; Nicandro con Teríacas y Geórgicas.

El nombre Geórgicas proviene del griego y alude al trabajo de la tierra, a los labradores o campesinos. La obra está constituida por cuatro partes. La primera se centra en el cultivo de los campos y el conocimiento de los signos del cielo. La segunda, en la cultura de los árboles y la vid. La tercera, en la crianza del ganado mayor y del ganado menor. Por fin, la cuarta se ocupa del arte de la apicultura.

Como las Bucólicas, esta obra posee una estructura arquitectónica basada en el equilibrio y la alternancia. Mientras en los libros primero y tercero se presentan matices oscuros, en los libros segundo y cuarto el carácter está más orientado hacia lo luminoso.

El primer libro presenta a la agricultura como esfuerzo, como labor ímproba. Ahora es el trabajo considerado indecente por la gente el que vence todo, a diferencia de lo que se afirmaba al final de las Bucólicas donde se decía que es el amor el que vence todo. También esta primera parte recoge el episodio de la muerte de César, anunciada por fenómenos del cielo, acontecimiento que sumió a Roma en un largo período de luchas intestinas. Análogamente, el otro libro impar, el tercero, culmina con una 
referencia a la peste y la destrucción que genera. En cambio, los libros pares, el segundo y el cuarto, balancean la atmósfera oscura con el elogio de la vida campesina, el segundo, y, el cuarto, con un hermoso epilio centrado en la historia de Aristeo, quien ve resurgir la vida después de obtener el perdón de los dioses. Él sacrifica reses para lograr tal perdón y observa cómo de las entrañas de esas reses surgen enjambres de abejas que lo compensan de la muerte de sus anteriores abejas.

\section{EL LECTOR DE HOY EN LOS MUNDOS DE LOS PASTORES, LOS AGRICULTORES Y LOS LÍDERES}

¿Qué implica el paso de las Bucólicas a las Geórgicas dentro de la obra de Virgilio? ¿Qué significa cada una de esas obras para el lector de hoy y para el lector de siempre? Son preguntas válidas e interesantes que podríamos plantearnos. No pretendo simplificar o reducir la complejidad de ninguna de las dos grandes obras virgilianas. Cada una de ellas es una joya artística de gran valor, un monumento invalorable construido con muchos elementos. Por ello es posible acercarse a ellas desde muy diversos puntos de vista: estilísticos, históricos, culturales, biográficos, estructurales, sociales, etc. Concretar una aproximación a tales obras desde todas esas perspectivas es imposible e inoportuno en una situación como la presente. Por ello, me limitaré a algunas ideas que considero importantes.

Virgilio se enriqueció con los estudios y con el conocimiento de una rica tradición poética y filosófica que fue adquiriendo a lo largo de su vida. Pero él, como autor, no se limitó a repetir o imitar. Vivió un verdadero proceso educativo en el que lo recibido se convirtió en estímulo para sacar de sí lo que solo podía venir como la miel de las abejas. La labor de creador es esa: acudir al néctar y el polen de las flores y elaborar con ellos la dulce 
miel y la útil cera. Las obras de arte con las que nos encontramos en la vida son esas flores, de las cuales podemos sacar lo que después será miel.

En las Bucólicas ofreció un maravilloso y complejo edificio en el que la vocación por la libertad y la felicidad se veía frustrada por causas externas a la persona o internas, las que nacen de la persona. La guerra y la injusticia son causas externas de tal frustración (y Virgilio las había probado). El amor pasional y la ambición son las causas internas. En esa obra, Virgilio expuso la complejidad de la vida representada en el mundo ideal de los pastores. El pastor encarna un modo de ser. Es el que aprovecha lo que ofrecen los campos para alimentar a su rebaño, con el cual se desplaza y consume lo que el medio natural produce. En cierto sentido podría decirse que es la tierra la que trabaja mientras que el hombre se limita a ser un consumidor. Ese escenario idílico, en el cual el hombre asume una actitud más pasiva que activa y desarrolla un oficio que poco exige del esfuerzo personal, ese escenario — decía - es el ambiente adecuado para reflejar el estado interior que corresponde a un tipo de hombre, como si se tratara de un reflejo o de un mundo de espejos. Me refiero a la condición del hombre pasivo o, en cierto sentido, pasional. Es el hombre que espera la felicidad y la imagina como inacción personal: hace depender todo solo de factores externos a él, los cuales pueden corresponder a la naturaleza o el azar. Ese tipo de individuo tiende a centrarse en sus goces y sus desgracias y no asume la construcción de su futuro ni elabora proyectos personales, y si lo hace pronto naufraga en el mar de la pasión o en lo aleatorio de la apuesta. Tiende a reducir su visión y su experiencia del amor a lo que alcanza su pasionalidad o a una inercia receptiva. Frecuentemente se agota en una actitud narcisista que siempre lo devuelve a su soledad porque el amor lo vence. En verdad, es el individuo derrotado por la pasión a la cual ha reducido al amor: no ha pasado de la condición de estar enamorado (situación pasiva) a la de amar (situación activa). 
Realidad muy diferente es la condición activa del amar. El hombre se hace activo y se constituye en persona cuando pasa de «estar enamorado» a «amar». En ese cambio deja la soledad del que centra todo en sí mismo y espera que la felicidad le venga de fuera. En condición activa, el hombre se decide a crear, a laborar, a labrar la tierra y su futuro. El trabajo, considerado indeseable antes, se vuelve camino de realización, y el hombre se descubre cocreador con la naturaleza, hija de Dios, y con Dios. Así, el hombre corresponde más a la imagen y la semejanza de Dios.

Al fin, todo exige labor, hasta el amar. Por ello, es gran descubrimiento aquel que ofrece la primera parte de las Geórgicas: «el indecente trabajo y la necesidad que urgen en las situaciones duras todo lo han vencido». Ya no es la dulce y engañosa pasión la que vence y domina. Ahora es el mal visto trabajo, el mal afamado trabajo, el que vence. Las Geórgicas presentan eso, el mundo activo y esforzado de la agricultura, de los labradores, los fruticultores, los ganaderos, los apicultores.

Después de tantos años de guerras que marcaron el fin de la República Romana y que destruyeron la economía y la agricultura, era necesario volver los ojos al campo; pero no al paisaje como refugio de pastores, sino al campo que exige cultura y, mediante ella, conduce a la gloria, al campo del trabajo esforzado que corresponde a la existencia humana en la tierra, al labor improbus. La labor del campesino se convierte en símbolo particular de todo el trabajo del hombre y en clave de interpretación de la existencia humana en sentido universal. El trabajo en Virgilio es ley inflexible y santa para el hombre, quien debe enfrentar incansablemente y con ingenio la condición efímera de los bienes, y debe operar entre la luz y la sombra, entre el amor y la muerte. Estamos ante el hombre que asume la construcción de su futuro y en pos de ello se vuelve activo. Crea mediante el trabajo y, gracias a él, deja 
de ser un mero individuo y asume el papel que debe y desea representar en el escenario de la vida. Así se vuelve persona, lo que supone no limitarse a aprovechar lo que la naturaleza ofrece o lo que la casualidad trae consigo, sino actuar y producir. Y esta labor que apunta a la prosperidad exige armonía y paz, con la naturaleza y con el prójimo. La tierra, en las Geórgicas, es un materno albergue de paz, a pesar de la condición disminuida en la que el hombre vive. El hombre de la época de Virgilio es consciente de que vive en la Edad de Hierro. El contacto con el campo induce a echar de menos la pasada felicidad de la Edad de Oro, de la mítica inocencia de la edad de Saturno, poblador de las tierras de Italia, y esa nostalgia genera el presentimiento de un mejor destino para la humanidad y se vuelve motor de la acción humana.

¿Cómo alcanzar un destino más alto? ¿Cuáles son los medios que el hombre debe emplear para encaminarse a ese fin? A esas preguntas responde, de alguna manera, la tercera obra de Virgilio, la Eneida, la epopeya de Eneas, el hombre del éxodo troyano. Eneas, en efecto, conduce a su derrotado pueblo a una tierra de promisión tras la destrucción de la sacra ciudad de Troya. Después de muchos padecimientos, llega a Italia, hogar de sus antepasados, la tierra de Saturno, allí se establece y sienta las bases de la futura Roma. Para concretar eso, Eneas ha debido asumir una misión, un encargo, que él ha convertido en su proyecto y, a pesar de los riesgos y de las seducciones, de las violencias y de las caídas, él ha cumplido. Es el hombre que no sucumbe ante el amor pasional encarnado por Dido y que no se deja vencer por el temor a los trabajos y las dificultades. Ardua es la empresa de fundar el linaje romano; pero él es el hombre fiel a la misión encomendada por el Fatum, el Hado. Es fiel a los dioses, a la patria, a la familia. Él encarna, pues, al hombre virtuoso movido por la pietas. De la pietas le viene la fuerza para cumplir su misión. Es importante anotar que no cumple su misión 
quien limita su visión del éxito a las aspiraciones individuales inmediatas o reduce su experiencia del amor a la pasión o la satisfacción de las exigencias primarias de lo que su naturaleza, el cuerpo, le pide. Esa misión tampoco es el fruto de la mera casualidad. La misión se alcanza con espíritu fiel y virtuoso; con amor no pasional, sino creador; con el esfuerzo aplicado al trabajo. El caudillo guía con su ejemplo y orienta su acción al beneficio del pueblo que conduce.

Desde nuestra experiencia de humanos de los siglos XX y XXI, cuánta nostalgia podemos sentir por la escasez de guías que comprendan y encarnen los valores que la poesía de Virgilio ha consagrado ¡Cuánto podrían aprender nuestros políticos, los conductores de la "polis», la ciudad, los constructores de la historia, si leyeran y asimilaran las enseñanzas que las grandes obras, las de los clásicos, nos han legado! ¡Cuánto bien podrían generar para sí y, en consecuencia, para la sociedad! Allí está Virgilio esperando nuestra lectura atenta. Allí está dispuesto a preguntar al lector: «Y tú, ¿qué piensas?; y tú, ¿qué haces?». Él, como experimentó Dante en su gran viaje de conversión que es la Divina Comedia, puede afinar nuestras capacidades de observación, de análisis, de comprensión de la complejidad y la riqueza del mundo. Él puede guiarnos por nuestros infiernos interiores; pero también puede inducirnos a cambiar e iniciar un proceso de purificación, puede acompañarnos en el discernimiento necesario para superar los sentimientos de culpa y devolvernos a la esperanza. Con él podemos volver a la vida después de la enfermedad. Sanos, y con la esperanza de la salud definitiva, podremos entregarnos a un amor más amplio que el de la pasión, el cual nos hará activos en el trabajo para construir un mundo mejor con la fuerza que otorga la fidelidad a Dios, la patria y la familia. 
Cuando tenía 19 años comencé a frecuentar a Virgilio. Desde entonces vivo un continuo y renovado asombro generado por la obra de este poeta. Lo conocí en la asignatura de Literatura Latina que cursaba como alumno del padre jesuita Pedro Cano. Por la misma época, Onorio Ferrero, destacado humanista italiano y profesor de la Pontificia Universidad Católica del Perú, me pidió que colaborara con él conduciendo un grupo de lectura de la Eneida integrado por alumnos del curso de Historia de la Cultura. Desde entonces Virgilio ha sido para mí un permanente punto de referencia. Mi aprecio por su obra aumentó cuando me asomé al mundo de Dante Alighieri. Este autor me enseñó a apreciar más a Virgilio y me mostró cuán vigente puede ser un clásico después de haber transcurrido siglos desde el momento en que concibió su obra. En efecto, por encima del vocerío de la época, de los gritos de la moda y del ruido político ensordecedor que producen en el ser humano experiencias de parálisis, adormecimiento o vértigo, un clásico puede suscitar lo contrario. Un clásico, aparentemente olvidado, distante, desactualizado, puede inducirnos a una experiencia de éxtasis, en la cual, a partir de un diálogo silencioso y profundo, sale de nosotros aquello que ya estaba impreso en nuestra interioridad. Y en eso, en el éxtasis, vivimos a plenitud. Frente al vértigo o el frenesí generados por el ruido o la droga que anulan nuestra voz y que producen momentos de transitoria y aparente felicidad, el éxtasis es fuente de experiencias más radicales, comprometedoras y estables. Para ello nos sirven los clásicos. Por eso Virgilio pudo guiar a Dante hasta la salud, hasta el estado edénico. Por eso pudo llevarlo de regreso a Beatriz, quien actuó como la conductora de Dante hacia la beatitud o felicidad eterna.

Los clásicos nos devuelven a la fe para que, teniendo fe, esperemos; y para que, esperando con confianza aquello en lo que tenemos fe, amemos. 
Para concluir, les digo que espero que la lectura de Virgilio nos sirva para darnos cuenta de que no podemos vivir limitados por el deseo de "pasarla bien», sino movidos por una voluntad más elevada, e inspirados por la utopía. Ojalá aprendamos de Virgilio que el hombre tiene una misión y que esta no se alcanza sin esfuerzo, sino con trabajo. Solo así construiremos la felicidad que todos deseamos y pregonamos. 


\section{BIBLIOGRAFÍA}

Bonifaz Nuño, Rubén

1967 Bucólica. México: Universidad Nacional Autónoma de México.

Borges, Jorge Luis

1999 Biblioteca personal. Madrid: Alianza.

HAEcker, Teodoro

1945 Virgilio. Padre de Occidente. Madrid: Sol y Luna.

Espinosa Polit, Aurelio

1932 Virgilio. El poeta y su misión providencial. Quito: Editorial Ecuatoriana.

VIRGILIO

2004 Bucólicas y Geórgicas. Lima: Fondo Editorial UCSS. 